Disponível em

http://www.anpad.org.br/rac

RAC, Rio de Janeiro, v. 19, n. 5, art. 3, pp. 584-605, Set./Out. 2015

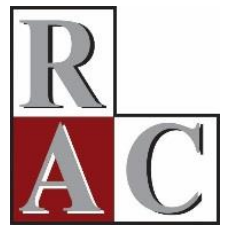

\title{
O Papel do Consultor no Processo de Alinhamento Estratégico
}

The Consultant's Role in the Strategic Alignment Process

Gustavo Abib Universidade Federal do Paraná - UFPR

Norberto Hoppen Universidade do Vale dos Sinos - UNISINOS

Artigo recebido em 01.04.2013. Última versão recebida em 10.04.2015. Aprovado em 12.05.2015. 


\title{
Resumo
}

O Alinhamento Estratégico (AE) entre a Tecnologia de Informação (TI) e os negócios continua sendo uma prioridade para os gestores, conforme estudos recentemente realizados em vários países. Contudo, como constataram outras pesquisas feitas sobre o tema, o AE não parece ser um processo prioritário e eficaz de planejamento e gestão no dia a dia da TI nas empresas. Também, com frequência, verifica-se a ação de consultores externos no desenvolvimento e na implementação de ferramentas de TI nas empresas, tanto para uso estratégico, como operacional. O papel do consultor no processo de AE é pouco enfatizado nas pesquisas. Considerando a importância da sua atuação na área de TI, este trabalho propõe a discussão do papel do consultor no processo de AE. Para tanto, foi analisada a implantação de um portal corporativo de natureza estratégica em uma empresa transnacional de grande porte. Neste estudo de caso longitudinal, adotaram-se observação participante e entrevistas semiestruturadas como principais estratégias para a coleta dos dados. Dentre os resultados obtidos, destacam-se o complexo papel do consultor, baseado em habilidades técnicas e sociopolíticas e, em especial, as necessidades de compartilhamento de conhecimentos. Evidenciaram-se, também, competências do consultor para tornar o seu papel mais efetivo no processo de AE.

Palavras-chave: alinhamento estratégico; tecnologia de informação; ator social; consultor externo.

\begin{abstract}
The Strategic Alignment (SA) between Information Technology (IT) and Business remains a priority for managers, according to recently realized studies in several countries. However, as found by a large number of the surveys on this subject, SA does not constitute a priority to companies when planning and implementing IT. Also, consultants often participate in the SA process, particularly to develop and implement IT devices, as much for strategic as operational purposes. The role of these consultants has not been sufficiently analyzed in research on SA. Considering the importance of the consultant's role in the SA process, our study proposes a discussion of this role as an external agent. Therefore, we analyzed the case of a strategic corporate portal developed in a large transnational company. We adopted participant observation and semi-structured interviews to collect data in this longitudinal case study. The main results we highlight are the complex roles of IT consultants during the AE process, based on their technical and sociopolitical knowledge and especially the need for knowledge sharing. Consultant skills were also necessary to fulfill more effective roles in the AE process.
\end{abstract}

Key words: strategic alignment; information technology; social actor; external consultant. 


\section{Introdução}

Os estudos de alinhamento têm sua origem na gestão estratégica das áreas de negócios e da área de Tecnologia da Informação (TI) (Chan \& Reich, 2007). Inicialmente, o planejamento era exclusivamente gerado pela cúpula (gestores) e disseminado para os níveis hierárquicos mais baixos (top-down). Posteriormente, a gestão estratégica também se desenvolveu no sentido inverso (bottom$u p$ ), buscando uma aproximação e um ajustamento de objetivos entre o negócio e a TI (Chan 2002; Henderson \& Venkatraman, 1993; Reich \& Benbasat, 1996), isto é, o Alinhamento Estratégico (AE).

Neste contexto, o tema AE está sendo estudado desde os anos 70. Profissionais e, principalmente, pesquisadores da área de TI buscam entender como se pode melhorar o alinhamento entre a TI e a estratégia organizacional em termos de suporte a processos de negócio e de disponibilização de informações (Chan \& Reich, 2007; Chan, Sabherwal, \& Thatcher, 2006; Grant, 2010; Luftman et al., 2012; Preston \& Karahanna, 2009).

Ao longo do tempo foram abordados temas como a avaliação do estágio de promoção (Luftman, 2000; Rigoni, Dwivedi, \& Hoppen, 2010), a influência de variáveis ambientais e comportamentais sobre o AE (Henderson \& Venkatraman, 1993), e a efetividade do AE (Ciborra, 1997). Estes motivaram, mais recentemente, a busca de um melhor entendimento sobre o papel dos diferentes atores no processo de alinhamento (Chan \& Reich, 2007; Ciborra, 2001; Lee, Kim, Paulson, \& Park, 2008).

Chan e Reich (2007) merecem destaque porque não enfatizam eficácia do AE, sob o argumento que a perspectiva mecanicista de muitas pesquisas não consegue capturar a situação real nas organizações e que o AE não é possível se a estratégia de negócios é pouco conhecida pelos atores ou está em processo de criação. As autoras também destacam que os atores envolvidos no processo de $\mathrm{AE}$ devem ser inquiridos nas pesquisas, reforçando a necessidade de mais estudos com base qualitativa para se compreender o alinhamento, posição também defendida por Ciborra (1997), e Tan e Gallup (2006). Estes últimos, inclusive, sustentam que o alinhamento tem um forte componente social e cultural, que pode ser observado no dia a dia dos envolvidos no processo de AE. O dia a dia no contexto da estratégia (Whittington, 2004) também são objetos de preocupação da abordagem estratégica enquanto prática.

Dado o avanço da tecnologia, do conhecimento necessário, e as mudanças nos processos de negócio, as empresas, ao adotar uma ferramenta de TI, muitas vezes recorrem a consultorias especializadas e à terceirização em geral para participarem da implantação desses novos artefatos (Meirelles, 2008). Esta situação é confirmada por estudo recente efetuado pela IBM junto a gestores de TI no Brasil e no mundo (Lobo, 2013). O referido estudo reporta que a terceirização da TI deixou de se preocupar majoritariamente com a redução de custos e, atualmente, envolve principalmente a inovação.

Nas pesquisas de $\mathrm{AE}$, o foco foi essencialmente o ator interno da empresa (de vários níveis hierárquicos ligados ao negócio e à TI) (Avgerou, Ciborra, \& Land, 2004; Chan et al., 2006). Os atores externos, que também influenciam o processo porque participam da implementação de ferramentas estratégicas, não foram contemplados nestes estudos. Por isso, dependendo das atividades previstas para o consultor, o seu papel no processo de AE pode se constituir como um importante foco de pesquisa.

Estudos desta natureza foram pouco desenvolvidos no Brasil e no exterior. Das raras pesquisas realizadas no Brasil sobre a ação de consultores de TI, H. J. Brodbeck, Brodbeck, Canépa e Bobsin (2010) estudaram os grupos sociais envolvidos na seleção, aquisição e implementação de ERP, incluindo os consultores, e Lunardi, Becker e Maçada (2010) analisaram a percepção dos consultores no impacto da adoção de mecanismos de governança de TI.

Esses estudos não contemplaram o papel do consultor de TI no processo de AE. Por tal razão, a presente pesquisa propõe um aprofundamento da análise do papel destes atores no processo de alinhamento, buscando discutir o papel do consultor de TI no processo de AE entre o negócio e a TI. Para tanto, o estudo fundamentou-se na literatura de $\mathrm{AE}$, na abordagem da estratégia enquanto prática e 
no papel do consultor de TI. Adotou-se o estudo de caso único e a observação participante como metodologia.

$\mathrm{Na}$ sequência desta introdução, são apresentados o referencial teórico, os procedimentos metodológicos, os resultados, as considerações relativas às bases teóricas e metodológicas do estudo, as suas contribuições e propostas para desenvolver o campo de estudos e o conhecimento sobre AE.

\section{Referencial Teórico}

$\mathrm{O}$ referencial teórico fundamenta-se nos conceitos de $\mathrm{AE}$, na abordagem da estratégia enquanto prática que viabiliza o estudo das atividades cotidianas dos atores de processos de implantação de estratégia, e nas competências e papéis dos consultores de TI.

\section{Alinhamento estratégico}

O AE entre negócio e TI pode ser definido como o grau no qual a missão, os objetivos e os planos contidos na estratégia de negócios da empresa suportam e são suportados pela estratégia de TI (Reich \& Benbasat, 1996). O alinhamento representa um processo de ajuste dinâmico e contínuo executado por pessoas (A. F. Brodbeck \& Hoppen, 2003).

Várias foram as abordagens adotadas para o estudo do AE (Joia \& Souza, 2009). As abordagens tradicionais de alinhamento tomaram por base um processo de planejamento predominantemente topdown, no qual os gestores desenvolvem um conjunto de planos estratégicos posteriormente implantados. Estes resultam em uma arquitetura de TI e estrutura de informações que se ajusta às estratégias de negócio da empresa. Outros elementos, que visam contribuir para a análise do $\mathrm{AE}$, foram buscados pela corrente crítica, tais como os atores sociais internos e externos, como também o alinhamento, não como um estado, mas sim como um processo (Chan \& Reich, 2007; Ciborra, 1997; Simonsen, 1999). Nos modelos tradicionais, esses aspectos estão contemplados, porém de maneira mais superficial.

A falta de entendimento do processo é causada, segundo Ciborra (1997), porque os pesquisadores privilegiam uma perspectiva mecanicista, com conexões causais diretas entre os conceitos abstratos que as compõem. O significado mais profundo dessas conexões permanece pouco conhecido. Assim, após a construção e a validação dos modelos de alinhamento, os pesquisadores encontram dificuldades na sua aplicação nas organizações.

Como o alinhamento envolve muitos atores, na prática é possível observar planos sendo alterados, eventos surpresa e ajustamentos oportunistas dos envolvidos de acordo com o momento vivido. Essas circunstâncias induzem o gestor a improvisar. Por isso, o alinhamento está ligado a uma percepção interna (da organização), uma maneira de lidar com os objetivos envolvidos (Ciborra, 1997).

Segundo Reich e Benbasat (2000), o desenvolvimento de um domínio compartilhado de conhecimento a partir de visões de curto e longo prazo favorece o alinhamento. Este processo possui características recursivas e é denominado de coevolução por Campbell e Peppard (2007). Isso porque é baseado em colaboração e compreensão mútua entre os envolvidos com o negócio e a TI.

Para melhor explorar o conhecimento sobre o processo de AE, a corrente crítica afirma ser necessário voltar ao dia a dia e às práticas rotineiras (Ciborra, 1997; Reich \& Benbasat, 2000). Por isso, abordou-se, no presente estudo, a análise do papel dos consultores no processo de AE sob a ótica da estratégia enquanto prática. 


\section{A estratégia enquanto prática}

A estratégia tem como função orientar uma organização através de mudanças e transições para assegurar seu futuro crescimento e sustentar seu sucesso. Isso se tornou uma importante diretriz para os altos gestores (CEOs) das empresas. A estratégia constitui-se como ponto obrigatório de ligação entre as organizações, muitas vezes fechadas, e o ambiente externo, onde a dinâmica do mercado se concretiza (Carter, Clegg, \& Kornberger, 2008).

Essa condição complexa, segundo Whittington (2004), pode ser mais bem compreendida com o retorno à razão prática da estratégia, isto é, na medida em que o observador se aproxima das atividades diárias, percebe a importância das pessoas envolvidas nesse processo.

$\mathrm{Na}$ visão de Whittington (2004), Jarzabkowski e Spee (2009), o crescimento da estratégia enquanto prática (SAP) e como campo de pesquisa deve-se à insatisfação com os métodos tradicionais de pesquisa. Enquanto as pessoas faziam a estratégia, a teoria estratégica era preenchida por análises multivariadas da firma relacionadas ao seu desempenho. Nessas abordagens, havia uma falha, pois não era analisado o papel dos atores e suas ações no processo estratégico.

Para Jarzabkowski e Spee (2009), alguns estudos seminais que consideraram o ator, focaram principalmente os CEOs como sendo a elite que poderia agir estrategicamente nas empresas. Porém, com o amadurecimento do campo, outros estudos englobaram os demais atores que participam do processo estratégico (Ciborra, 2001).

Recentemente, a pesquisa em estratégia voltou seu foco para as atividades diárias dos praticantes da estratégia. Essa abordagem defende que a estratégia pode ser compreendida através do que as pessoas fazem e não somente do que as empresas e seus mercados possuem. Enquanto Johnson, Melin e Whittington (2003) privilegiaram as atividades diárias (microatividades) que moldam os resultados estratégicos, outros autores mencionaram que, para melhor entender as microatividades, o pesquisador deve levar em consideração o seu contexto organizacional (Maciel \& Augusto, 2013). Vale ressaltar que os atores não agem independentemente deste contexto, pois nele constroem seus relacionamentos e interagem com as estruturas sociais (Balogun, Jarzabkowski, \& Seidl, 2007; Jarzabkowski \& Seidl, 2008; Whittington, 2006).

A questão da articulação entre micro e macro surgiu por causa do foco no estudo dos praticantes (os atores envolvidos no processo), e das práticas e práxis como microfenômenos. Entretanto, esse tipo de estudo só se torna válido quando também se analisa o macro (intenções, interações e ambiente), no qual a estratégia é construída, implementada e validada (Ciborra, 2002; Whittington, 2006).

Nessa linha, o presente estudo procurou analisar as relações complexas entre os atores envolvidos no processo de AE. Para tanto, os três níveis foram analisados, sendo eles: os idealizadores da estratégia (nível macro), os mediadores da sua execução (nível meso) - gestores e consultores externos - e os executores da estratégia (nível micro), que compreende usuários e analistas.

Com a introdução do fenômeno denominado de drifting por Ciborra (2002), o foco recaiu sobre as práxis dos atores, ou seja, suas atividades cotidianas. Para esse autor, muitos fenômenos cotidianos são contingências e surgem de maneira não previsível. Dessa forma, para se analisar o alinhamento, deve-se observar os processos explícitos e emergentes ou os contingenciais. Para Ciborra, o alinhamento é um fenômeno processual e, ao se analisar a práxis, verifica-se que esta é resultante de processos planejados e emergentes.

Para um melhor entendimento, é sobremodo importante analisar os microprocessos nos quais estão envolvidos os atores sociais. Esta proposta de retorno às práticas não é uma tentativa de se desprezar as contribuições advindas do campo teórico da estratégia, mas sim um grande desafio intelectual em tornar a estratégia e o AE mais eficientes (Ciborra, 1997, 2001; Wilson \& Jarzabkowski, 2004). 


\section{O papel dos consultores de TI}

O consultor de TI trabalha em parceria com o cliente, aconselhando-o na estruturação, na implementação e no uso da tecnologia, a fim de cumprir os objetivos de caráter estratégico, tático e operacional almejados. Vários são os focos de trabalho dos consultores, destacando-se, segundo Prospects (2012): (a) melhorar a estrutura e a eficiência da TI; (b) orientar estrategicamente a empresa na aquisição de tecnologia; (c) definir escopos de projeto; (d) implementar tecnologias; e (e) auxiliar no alinhamento estratégico entre a TI e os negócios. Para atingir esses propósitos, Bloomfield e Danieli (1995) afirmam que os consultores de TI devem possuir duas características essenciais: habilidades técnicas e sociopolíticas.

As habilidades técnicas compreendem o domínio da ferramenta tecnológica e suas melhores práticas de uso. Já as habilidades sociopolíticas incluem a percepção de impactos potenciais da implantação das ferramentas, da comunicação, negociação, persuasão e dos fatores relacionados a conflitos de interesses e a inclusão destes elementos no seu trabalho cotidiano. Dentre estes, a comunicação é um dos elementos mais importantes na avaliação do AE entre o negócio e a TI (Luftman, 2000).

Como há diferentes contextos e tipos de consultoria de TI, optou-se por adotar o referencial de Ruhl (1997), que sistematiza os tipos de consultores de TI e as atividades por eles realizadas (ver Tabela 1).

Tabela 1

\section{Tipos de Consultores em TI}

\begin{tabular}{|c|c|c|}
\hline Contexto & Tipo & Trabalho Realizado \\
\hline \multirow[t]{3}{*}{ Técnico } & Programador de Contratos & $\begin{array}{l}\text { Codificar, testar, sendo remunerado por hora. Pode também } \\
\text { fazer design e trabalho de análise. }\end{array}$ \\
\hline & Revendedor/Integrador de Sistemas & $\begin{array}{l}\text { Selecionar e configurar software e hardware. Compra por } \\
\text { atacado, buscando necessidades dos clientes. }\end{array}$ \\
\hline & Consultores em Mídias e Web & $\begin{array}{l}\text { Projetar e desenvolver material de multimídia e web. } \\
\text { Projetar e desenvolver material pedagógico para } \\
\text { treinamento. }\end{array}$ \\
\hline \multirow[t]{2}{*}{ Gerencial } & Consultor Especialista & $\begin{array}{l}\text { Aconselhar diretores em estratégias e políticas ou opções } \\
\text { técnicas. Ministrar seminários e workshops. } \\
\text { Frequentemente citado na empresa. }\end{array}$ \\
\hline & Consultor em Gestão de TI & $\begin{array}{l}\text { Administrar projetos, elaborar de relatórios, estudos, } \\
\text { análises e resolução de problemas. }\end{array}$ \\
\hline
\end{tabular}

Nota. Fonte: Adaptado de Ruhl, J. (1997). The computer consultant's guide (2nd. ed., p. 5). New York: John Wiley \& Sons.

Em estudo sobre o mercado de consultoria do Brasil nos anos 90, Donadone (1995) verificou que muitas consultorias são contratadas para introduzir ferramentas de TI nas organizações. Correia, Feitosa e Vieira (2010), por sua vez, ressaltaram a necessidade de deixar claro o papel do cliente e do consultor no processo de consultoria no momento da contratação e durante o processo. Já de acordo com Markus e Benjamin (1996), os consultores de TI atuam (ou deveriam atuar) como agentes de mudança, através de intervenções sociais.

Contudo, em conversas mantidas com profissionais da área que atuam como consultores, notouse que os contratos assinados contemplam, predominantemente, o contexto técnico (projeto e implementação de sistemas, seleção de softwares). Os aspectos relacionados com o contexto social e de negócio, tais como aquisição de conhecimento (mais aprofundado) sobre a estratégia e o negócio da contratante, são menos detalhados. 
Com base nos autores mencionados e nas conversas mantidas com profissionais, verifica-se que é necessário melhorar a atuação organizacional dos consultores de TI, uma vez que o conhecimento do negócio e da estrutura da organização (Correia, Feitosa, \& Vieira, 2010), o conhecimento da estratégia (os profissionais consultados), o processo de mudança (Markus \& Benjamin, 1996) e o conhecimento da cultura por vezes são mais importantes que a própria tecnologia.

Os elementos essenciais do referencial teórico do estudo acerca do AE, do papel dos atores, em especial dos consultores, e a estratégia enquanto prática, estão sintetizados na Figura 1.

\begin{tabular}{|c|c|c|c|}
\hline CONTEXTO ATORES & $\begin{array}{l}\text { INTERNO } \\
\text { (Negócio e T.I. }\end{array}$ & & $\begin{array}{l}\text { EXTERNO } \\
\text { (Consultores) }\end{array}$ \\
\hline TÉCNICO & \multirow{2}{*}{ Papéis } & \multirow{2}{*}{ Relacionamentos } & \multirow{2}{*}{ Práxis } \\
\hline GERENCIAL & & & \\
\hline
\end{tabular}

Figura 1. O Papel do Consultor no Processo de AE

Fonte: Elaborado pelos autores

Dentre os elementos da Figura 1, o contexto ou caráter técnico ou gerencial das ações foi obtido de Ruhl (1997), e as práxis dos atores e os relacionamentos estabelecidos originaram-se da abordagem SAP (Jarzabkowski \& Spee, 2009; Whittington, 2006).

\section{Método e Contexto}

\section{O contexto}

A empresa selecionada, denominada TESLA (nome fictício), é subsidiária de uma empresa transnacional com mais de R $\$ 100$ bilhões de dólares em ativos, atuando em segmentos industriais como metalurgia e energia. A TESLA é do setor de energia, sendo uma das mais rentáveis desse setor. No ano em que foi realizada a pesquisa, ela obteve uma receita operacional líquida de $\mathrm{R} \$ 478,6$ milhões, contava com 380 colaboradores e tinha 34 usinas operando nas regiões sul, sudeste e centro-oeste.

Analisou-se a implantação de um portal corporativo que deveria servir como suporte para o negócio da empresa, com o propósito de melhorar a comunicação e a colaboração entre equipes e departamentos, e ainda apoiar sua gestão e integração. O orçamento inicialmente alocado pela empresa foi de R \$ 2 milhões, compreendendo infraestrutura e contratação de uma empresa de consultoria. Ao todo, 63 pessoas de diversos setores da empresa se envolveram com o projeto.

Para o portal corporativo, foram previstas funcionalidades para: (a) a divulgação da missão e da visão estratégica dos objetivos, das metas e ações previstas para os departamentos, dos indicadores de desempenho e da estrutura orgânica; (b) a disponibilização de um banco de documentos e de um banco de imagens; e (c) a disponibilização de um mecanismo de busca. Muitas dessas funcionalidades faziam parte do planejamento estratégico da empresa. No que diz respeito à estrutura orgânica, cabe salientar que ela era essencialmente matricial, com pessoas e setores diferentes trabalhando em diversos projetos paralelos.

Visando apoiar o processo de implantação do novo portal, TESLA contratou uma consultoria externa, conhecedora das melhores práticas para a implementação desse tipo de ferramenta de TI. As recomendações desse ator externo, em geral, prevalecem e são as adotadas pelas empresas, pois parte- 
se do princípio de que o consultor é um especialista neste assunto e tem experiência com a ferramenta e com a sua operacionalização. A empresa de consultoria alocou uma equipe de 12 consultores, além de uma equipe de suporte que não atuava diretamente na empresa TESLA. A equipe de consultores era formada por um gestor e um analista de negócios com visão macro e estratégica do portal, e por técnicos operacionais que dominavam a ferramenta.

Foram observados cinco diferentes setores da empresa: os departamentos de recursos humanos $(\mathrm{RH})$, meio ambiente e segurança (nos quais a implantação do portal se iniciou, propiciando mais tempo de observação), a direção geral e de TI, o departamento de TI e a consultoria externa.

\section{O método}

Visando atingir o objetivo proposto, o estudo de caso longitudinal único foi utilizado como estratégia de investigação (Yin, 2005). Para a coleta dos dados, optou-se pela observação participante e por entrevistas semiestruturadas. A escolha dessas estratégias se deu porque buscou-se compreender o papel do consultor em um processo de $\mathrm{AE}$ em um contexto natural, procurando destacar os elementos que emergiram do campo ao longo da pesquisa. Uma pesquisa longitudinal dessa natureza, com a possibilidade de capturar e atribuir significado a fenômenos de caráter subjetivo, raramente é viável por ser um processo pouco acessível aos não envolvidos diretamente.

As potenciais contribuições da metodologia qualitativa que motivaram a sua adoção nesta pesquisa foram: (a) a necessidade de sair a campo para descobrir o que realmente está acontecendo (consultores atuando no processo de AE); (b) a complexidade e a variabilidade dos fenômenos e das ações humanas; (c) a crença de que as pessoas são atores que assumem um papel ativo para responder a situações problemáticas; (d) o entendimento de que o significado é definido e redefinido através da interação; e (e) a consciência das inter-relações entre condições (estrutura), ação (processo) e consequências (Strauss \& Corbin, 2008).

A escolha de TESLA como campo de observação foi motivada pela possibilidade de acessar uma empresa competitiva no seu segmento de negócio, a qual ofereceu condições históricas para acompanhar, desde o início, o projeto de implantação de um portal estratégico em vários dos seus departamentos.

Esta implantação contou com a participação de consultores, cujo papel é objeto deste estudo. Nesse campo, foram reunidos, respectivamente, os principais elementos necessários para a pesquisa: planejamento estratégico, ferramenta de TI de natureza estratégica, presença de consultores e processo de implementação. Iniciou-se, assim, um estudo de caso único revelador (Yin, 2005).

Para efetivar a observação participante prevista, um dos autores teve a oportunidade de acompanhar o processo de implementação como pesquisador, sem fazer parte do quadro funcional da empresa ou do quadro de consultores. A esse pesquisador foi atribuído o papel de analista de processos, vinculado ao departamento de TI (gestor do projeto), com o propósito de ter livre trânsito, acesso aos consultores e autonomia para observar e fazer questionamentos nos departamentos e níveis hierárquicos envolvidos no projeto.

Os dados foram coletados de várias formas: por observação participante e direta, a partir de entrevistas, análise de documentos do portal e de arquivos digitais. A observação participante foi selecionada como principal método de coleta para observar as interações (ações, eventos) e experiências relacionadas ao processo de implementação do portal (Abib, Hoppen, \& Hayashi, 2013; Angrosino, 2009). As categorias (os construtos) que embasaram a coleta sistemática de dados foram os atores, seu contexto e os papéis resultantes deste, os relacionamentos, as práticas, a práxis e a tecnologia. Essas categorias originaram-se do referencial teórico e foram julgadas adequadas para estudar a dimensão social no processo de $\mathrm{AE}$.

O emprego da observação participante em uma pesquisa requer, muitas vezes, uma complementação com outras metodologias como, por exemplo, com entrevistas (Serva \& Jaime, 1995). 
Durante a pesquisa, foram realizadas entrevistas do tipo etnográfica, em que há apenas algumas questões introdutórias e o restante é conduzido pelo pesquisador (Trauth \& O'Connor, 1991). As entrevistas foram realizadas em situações nas quais se necessitava de mais dados para analisar o fenômeno ou dirimir alguma dúvida. Buscou-se três tipos de dados: (a) aspectos técnicos sobre a tecnologia que estava sendo estudada (funcionalidades); (b) percepção das pessoas frente a essa tecnologia; e (c) informações que resultaram a partir daquilo que não foi dito ou o que ficou diferente das observações realizadas, tal como a real importância do portal para a estratégia da empresa.

$\mathrm{Na}$ observação direta, analisou-se a ferramenta do portal corporativo, objeto do trabalho dos consultores, em especial a percepção dos usuários, sua operação técnica e também seu alinhamento com a estratégia.

Durante o trabalho no campo, surgiram armadilhas para a manutenção do rigor metodológico porque, com o propósito de tornar o processo de coleta menos intrusivo, nenhuma conversa foi gravada. Para minimizar esse inconveniente, as anotações foram efetuadas durante ou logo após cada evento. Elas foram revisadas quando da sua digitalização, buscando assim preservar a sua exatidão. Ao longo da pesquisa de campo foram realizadas 29 reuniões e coletadas 79 páginas de anotações, contendo desenhos, citações, reflexões e informações gerais. A coleta durou 12 meses.

A diversidade de fontes e a complexidade das interações envolvidas levaram o pesquisador a confirmar suas percepções e os resultados emergentes através da triangulação de dados e de verificações junto aos atores envolvidos. Por exemplo, quando em algumas reuniões não ficava evidente a posição favorável ou contrária ao portal de determinado participante devido à sua pequena participação, recorreu-se a dados originados de entrevistas e à análise do portal (funcionalidades e uso) sob sua responsabilidade. Com a triangulação, pode-se então identificar a posição do participante face ao projeto.

A análise dos dados fundamentou-se em uma análise de conteúdo do tipo categórica, a partir das cinco categorias já adotadas na coleta, com destaque para o papel do consultor. Também foi realizada uma análise temporal do processo de implantação, visando evidenciar a interação social entre os atores e o artefato tecnológico. O processo de análise dos dados se deu em dois momentos distintos: quando da observação e da coleta dos dados, o que permitiu formular novos questionamentos, e da integração final de todos os dados coletados.

Para esse tipo de pesquisa, Kirk e Miller (1986) entendem como validade o grau com que os resultados são interpretados de modo correto e, como confiabilidade, o grau com que determinado resultado independe de circunstâncias acidentais. Por sua vez, segundo Dubé e Paré (2003), a validade e a confiabilidade da pesquisa podem ser incrementadas através da triangulação de vários tipos de dados coletados, da verificação dos resultados com os entrevistados e da coleta de dados em diferentes contextos (níveis hierárquicos, departamentos e atores externos).

Neste estudo, a validade de construto baseou-se no uso de múltiplas fontes de evidência na coleta e na análise dos dados, tais como: documentos, registros em arquivos (privados), entrevistas e observações diretas (reuniões, hora do cafezinho, etc.). Além disto, relatórios contendo resultados foram apresentados a informantes-chave para reforçar a consistência das análises. A confiabilidade fundamentou-se na revisão da codificação para reduzir as inconsistências e melhorar a exatidão (Krippendorff, 1980), e na reiterada revisão dos objetivos da pesquisa pelo pesquisador, com o propósito de padronizar a coleta e a análise dos dados.

\section{Resultados}

A análise dos resultados fundamentou-se na questão de pesquisa, abordada sob a ótica da estratégia enquanto prática: Qual o papel do consultor no processo de AE entre o negócio e a TI? Os questionamentos específicos importantes para a coleta e análise dos dados foram: Qual o 
conhecimento que o consultor tem dos objetivos iniciais do projeto e da estratégia corporativa de TESLA? e Qual a importância destes conhecimentos para atingir o AE?

Os dados coletados e codificados foram categorizados por nível hierárquico e departamento, segundo os atores envolvidos, e por atividades-chave que incluem práticas, práxis e relacionamentos. A categorização e a análise das atividades-chave basearam-se no referencial teórico sintetizado na Figura 1. Os resultados obtidos para o nível hierárquico, direção geral e de TI estão detalhados na Tabela 2.

Tabela 2

Direção Geral e de TI: Tipos de Ações no Processo de Implantação do Portal

\begin{tabular}{|c|c|c|c|c|c|c|}
\hline \multirow{3}{*}{$\begin{array}{l}\text { Áreas e } \\
\text { participantes }\end{array}$} & \multirow{2}{*}{\multicolumn{2}{|c|}{$\begin{array}{l}\text { Contexto Técnico } \\
\text { Atividade-chave: projetar } \\
\text { e desenvolver o portal }\end{array}$}} & \multicolumn{4}{|c|}{ Contexto Gerencial } \\
\hline & & & \multicolumn{2}{|c|}{$\begin{array}{l}\text { Atividade-chave: aconselhar os } \\
\text { dirigentes em estratégias e } \\
\text { opções técnicas }\end{array}$} & \multicolumn{2}{|c|}{$\begin{array}{l}\text { Atividade-chave: administrar o } \\
\text { projeto, resolver problemas }\end{array}$} \\
\hline & TESLA & Consultores & TESLA & Consultores & TESLA & Consultores \\
\hline $\begin{array}{l}\text { Direção: } \\
\text { Presidente e } \\
\text { Diretor de } \\
\text { TI }\end{array}$ & $\begin{array}{l}\text { Tanto o } \\
\text { presidente } \\
\text { como o } \\
\text { diretor de TI } \\
\text { não tiveram } \\
\text { contato com } \\
\text { o contexto } \\
\text { técnico. }\end{array}$ & $\begin{array}{l}\text { Não tiveram } \\
\text { contato com } \\
\text { o nível } \\
\text { estratégico } \\
\text { da empresa } \\
\text { em nenhum } \\
\text { momento do } \\
\text { projeto. }\end{array}$ & $\begin{array}{l}\text { Definir os } \\
\text { objetivos } \\
\text { estratégicos do } \\
\text { portal: suporte } \\
\text { ao processo } \\
\text { decisório e } \\
\text { disponibilização } \\
\text { de informações } \\
\text { de gestão } \\
\text { (indicadores). }\end{array}$ & $\begin{array}{l}\text { Sem contato } \\
\text { direto com a } \\
\text { presidência. Os } \\
\text { contatos com o } \\
\text { diretor de TI } \\
\text { para análise } \\
\text { estratégica } \\
\text { foram feitos } \\
\text { antes do início } \\
\text { do projeto e na } \\
\text { segunda } \\
\text { renovação do } \\
\text { banco de horas. }\end{array}$ & $\begin{array}{l}\text { O presidente } \\
\text { era informado } \\
\text { sobre o projeto } \\
\text { através de } \\
\text { relatos feitos } \\
\text { pelo diretor de } \\
\text { TI. Este as } \\
\text { recebia do seu } \\
\text { usuário-chave. }\end{array}$ & $\begin{array}{l}\text { Sem contato } \\
\text { com a } \\
\text { presidência. Os } \\
\text { contatos com o } \\
\text { diretor de TI } \\
\text { ocorreram } \\
\text { somente } \\
\text { quando da } \\
\text { apresentação } \\
\text { dos relatórios } \\
\text { finais de } \\
\text { entrega de } \\
\text { etapas. }\end{array}$ \\
\hline
\end{tabular}

Nota. Fonte: Dados primários

Desde a contratação até a implantação do portal, em momento algum o consultor, em especial o analista de negócios, teve contato com a área estratégica da empresa (o presidente). Os objetivos do portal foram repassados pelo diretor de TI em uma reunião formal que ocorreu no início do projeto. Não ocorreram reuniões de reforço. Também houve pouco contato do diretor de TI com o consultor-analista e os demais, porque o departamento de TI alocou um usuário-chave do seu setor para acompanhar e gerenciar esse projeto. A este respeito, o diretor de TI mencionou: "O Breno (nome fictício) é uma pessoa muito dinâmica e conhece muito da área de tecnologia, ele tem total capacidade para acompanhar o projeto e, se tiver algum problema, ele me chama." Tabela 3.

Os resultados obtidos para o nível hierárquico tático TI - usuários-chave - estão detalhados na 
Tabela 3

TI - Usuários-Chave: Tipos de Ações no Processo de Implantação do Portal

\begin{tabular}{|c|c|c|c|c|c|c|}
\hline \multirow{3}{*}{$\begin{array}{l}\text { Áreas e } \\
\text { participantes }\end{array}$} & \multirow{2}{*}{\multicolumn{2}{|c|}{$\begin{array}{l}\text { Contexto Técnico } \\
\text { Atividade-chave: projetar e } \\
\text { desenvolver o portal. }\end{array}$}} & \multicolumn{4}{|c|}{ Contexto Gerencial } \\
\hline & & & \multicolumn{2}{|c|}{$\begin{array}{l}\text { Atividade-chave: aconselhar } \\
\text { os dirigentes em estratégias e } \\
\text { opções técnicas. }\end{array}$} & \multicolumn{2}{|c|}{$\begin{array}{l}\text { Atividade-chave: administrar } \\
\text { o projeto, resolver problemas. }\end{array}$} \\
\hline & TESLA & Consultores & TESLA & Consultores & TESLA & Consultores \\
\hline $\begin{array}{l}\text { TI - usuário- } \\
\text { chave }\end{array}$ & $\begin{array}{l}\text { Elo de ligação } \\
\text { entre os } \\
\text { consultores e a } \\
\text { empresa. } \\
\text { Atuou e } \\
\text { aprovou as } \\
\text { funcionalidade } \\
\text { s operacionais } \\
\text { do portal. }\end{array}$ & $\begin{array}{l}\text { Todos os } \\
\text { contatos } \\
\text { operacionais } \\
\text { relativos a } \\
\text { funcionalidades } \\
\text { e a bancos de } \\
\text { hora eram } \\
\text { negociados } \\
\text { diretamente } \\
\text { com este } \\
\text { usuário que } \\
\text { coordenava o } \\
\text { projeto. }\end{array}$ & $\begin{array}{l}\text { Por possuir } \\
\text { uma visão } \\
\text { limitada da } \\
\text { estratégia } \\
\text { corporativa e } \\
\text { de cada } \\
\text { departamento, } \\
\text { as orientações } \\
\text { para os } \\
\text { consultores } \\
\text { em relação } \\
\text { aos objetivos } \\
\text { traçados pela } \\
\text { presidência } \\
\text { eram } \\
\text { limitadas. }\end{array}$ & $\begin{array}{l}\text { Pela limitação } \\
\text { de visão } \\
\text { estratégica, } \\
\text { projetavam } \\
\text { soluções mais } \\
\text { operacionais, } \\
\text { visando } \\
\text { atender aos } \\
\text { objetivos } \\
\text { individuais. }\end{array}$ & $\begin{array}{l}\text { Nesta parte, o } \\
\text { usuário- } \\
\text { chave possuía } \\
\text { total } \\
\text { autonomia } \\
\text { para } \\
\text { administrar os } \\
\text { recursos do } \\
\text { projeto (ex. } \\
\text { banco de } \\
\text { horas). }\end{array}$ & $\begin{array}{l}\text { Os dois } \\
\text { consultores } \\
\text { líderes } \\
\text { atuavam } \\
\text { diretamente } \\
\text { com o usuário } \\
\text { de TI, } \\
\text { apontando as } \\
\text { demandas de } \\
\text { cada } \\
\text { departamento, } \\
\text { buscando } \\
\text { legitimar suas } \\
\text { ações. }\end{array}$ \\
\hline
\end{tabular}

Nota. Fonte: Dados primários.

Os gestores da TESLA escolheram alguns usuários-chave departamentais para acompanhar a implantação do portal. Esses usuários-chave, por deterem mais conhecimento sobre o negócio, além de coordenarem as implantações nos seus respectivos departamentos, serviram de elo entre a TESLA e os consultores. A participação desses usuários foi ativa em todas as fases do projeto: apresentação inicial, discussão coletiva e individual de necessidades, validação do desenho e do protótipo da solução, treinamento e ajustes finais.

Conforme apresentado na Tabela 3, a preocupação com o portal voltou-se essencialmente para aspectos operacionais. As palavras de um usuário-chave departamental sobre o objetivo do portal ilustram isso: "controlar documentos, publicar licenças ambientais e centralizar o controle sobre os mesmos" (Inf-04). Outro usuário do mesmo departamento ainda aponta: "O portal servirá para substituir os atuais recursos de rede - controle e publicação" (Inf-05).

Ao analisar os objetivos do portal apresentados pelos consultores nas diversas reuniões com as áreas, verificou-se uma mescla de objetivos estratégicos (ex. aumentar o alinhamento estratégico) com objetivos operacionais (por exemplo, reduzir o volume de informações enviadas por $e$-mail). Processos e atividades do contexto gerencial foram minimamente contemplados. A influência dos consultores sobre os usuários-chave departamentais foi grande porque, em geral, eles estavam em maior número nas reuniões e conheciam detalhadamente a ferramenta a ser implantada. Essa influência se refletiu na abrangência da solução, nas funcionalidades do portal e no seu funcionamento.

O resultado obtido para o nível hierárquico tático e operacional, formado pelos gestores e funcionários (os principais usuários) dos três departamentos analisados, está detalhado na Tabela 4. 
Tabela 4

Departamentos - Gestores e Funcionários: Tipos de Ações no Processo de Implantação do Portal

\begin{tabular}{|c|c|c|c|c|c|c|}
\hline \multirow{3}{*}{$\begin{array}{l}\text { Áreas e } \\
\text { participantes }\end{array}$} & \multirow{2}{*}{\multicolumn{2}{|c|}{$\begin{array}{l}\text { Contexto Técnico } \\
\text { Atividade-chave: projetar e desenvolver o portal }\end{array}$}} & \multicolumn{4}{|l|}{ Contexto Gerencial } \\
\hline & & & \multicolumn{2}{|c|}{$\begin{array}{l}\text { Atividade-chave: aconselhar os dirigentes em } \\
\text { estratégias e opções técnicas }\end{array}$} & \multicolumn{2}{|c|}{$\begin{array}{l}\text { Atividade-chave: administrar o projeto, resolver } \\
\text { problemas }\end{array}$} \\
\hline & TESLA & Consultores & TESLA & Consultores & TESLA & Consultores \\
\hline $\begin{array}{l}\text { RH: Gestor e } \\
\text { funcionários }\end{array}$ & $\begin{array}{l}\text { O gestor não participou } \\
\text { das atividades } \\
\text { operacionais, tampouco } \\
\text { esteve presente. O } \\
\text { usuário-chave deste } \\
\text { departamento assumiu } \\
\text { toda a parte de } \\
\text { estruturação para si, } \\
\text { alinhando as suas } \\
\text { necessidades com as } \\
\text { funcionalidades do } \\
\text { portal. }\end{array}$ & $\begin{array}{l}\text { Pela falta do gestor, } \\
\text { todas as solicitações do } \\
\text { usuário-chave deste } \\
\text { departamento, todas as } \\
\text { solicitações, foram } \\
\text { negociadas diretamente } \\
\text { com os consultores e } \\
\text { foram prontamente } \\
\text { atendidas. A satisfação } \\
\text { do usuário-chave foi } \\
\text { total. }\end{array}$ & $\begin{array}{l}\text { O gestor não participou } \\
\text { das reuniões de } \\
\text { desenho do portal e das } \\
\text { reuniões de } \\
\text { acompanhamento, } \\
\text { faltando no processo } \\
\text { uma visão mais de } \\
\text { gestão. Apenas } \\
\text { funcionalidades } \\
\text { operacionais foram } \\
\text { solicitadas e entregues } \\
\text { ao departamento }\end{array}$ & $\begin{array}{l}\text { Os consultores não } \\
\text { conheciam o } \\
\text { direcionamento } \\
\text { estratégico do } \\
\text { departamento e, nas } \\
\text { reuniões de desenho do } \\
\text { portal, ofereceram as } \\
\text { soluções operacionais } \\
\text { padrão, aceitas pelo } \\
\text { usuário-chave. }\end{array}$ & $\begin{array}{l}\text { O gestor delegou toda a } \\
\text { gestão de implantação } \\
\text { do portal para seu } \\
\text { usuário chave. O } \\
\text { usuário-chave, por sua } \\
\text { vez, negociava } \\
\text { diretamente com a TI e } \\
\text { com a consultoria. }\end{array}$ & $\begin{array}{l}\text { O contato geralmente } \\
\text { era de um consultor } \\
\text { técnico no dia a dia que } \\
\text { repassava os problemas } \\
\text { a um consultor líder. } \\
\text { Apresentavam somente } \\
\text { relatórios básicos de } \\
\text { acompanhamento. }\end{array}$ \\
\hline $\begin{array}{l}\text { Segurança } \\
\text { Gestor e } \\
\text { funcionários }\end{array}$ & $\begin{array}{l}\text { O diretor de segurança } \\
\text { atuou intensamente no } \\
\text { desenho, } \\
\text { implementação e } \\
\text { operacionalização do } \\
\text { portal. Já possuía } \\
\text { experiência com portais } \\
\text { e alinhou os objetivos } \\
\text { estratégicos do } \\
\text { departamento com as } \\
\text { funcionalidades do } \\
\text { portal. }\end{array}$ & $\begin{array}{l}\text { Mesmo em se tratando } \\
\text { de aspectos técnicos, a } \\
\text { negociação era } \\
\text { realizada diretamente } \\
\text { com os consultores } \\
\text { líderes que passavam } \\
\text { as necessidades aos } \\
\text { consultores técnicos } \\
\text { alocados na empresa. }\end{array}$ & $\begin{array}{l}\text { O diretor de segurança } \\
\text { foi o ator mais presente } \\
\text { no processo. Por ser } \\
\text { diretor tinha acesso aos } \\
\text { direcionamentos } \\
\text { estratégicos da empresa } \\
\text { e contato direto com o } \\
\text { presidente. }\end{array}$ & $\begin{array}{l}\text { Neste departamento, os } \\
\text { consultores discutiam } \\
\text { soluções mais } \\
\text { estratégicas do portal } \\
\text { como, por exemplo, a } \\
\text { implantação de } \\
\text { indicadores de } \\
\text { performance, entre } \\
\text { outras ferramentas, de } \\
\text { suporte a decisão. }\end{array}$ & $\begin{array}{l}\text { O gestor do } \\
\text { departamento assumiu } \\
\text { toda a coordenação do } \\
\text { projeto e, por estar no } \\
\text { mesmo nível do gestor } \\
\text { de TI, em alguns casos } \\
\text { negociou mais horas de } \\
\text { consultoria para o seu } \\
\text { departamento. }\end{array}$ & $\begin{array}{l}\text { Neste departamento, } \\
\text { especificamente, toda a } \\
\text { gestão era feita pelos } \\
\text { dois consultores } \\
\text { líderes. Sempre com } \\
\text { novas demandas, os } \\
\text { consultores } \\
\text { providenciavam } \\
\text { estudos de viabilidade } \\
\text { e as reuniões eram } \\
\text { frequentes. }\end{array}$ \\
\hline
\end{tabular}


Tabela 4 (continuação)

\begin{tabular}{|c|c|c|c|c|c|c|}
\hline \multirow{3}{*}{$\begin{array}{l}\text { Áreas e } \\
\text { participantes }\end{array}$} & \multirow{2}{*}{\multicolumn{2}{|c|}{$\begin{array}{l}\text { Contexto Técnico } \\
\text { Atividade-chave: projetar e desenvolver o portal }\end{array}$}} & \multicolumn{4}{|l|}{ Contexto Gerencial } \\
\hline & & & \multicolumn{2}{|c|}{$\begin{array}{l}\text { Atividade-chave: aconselhar os dirigentes em } \\
\text { estratégias e opções técnicas }\end{array}$} & \multicolumn{2}{|c|}{$\begin{array}{l}\text { Atividade-chave: administrar o projeto, resolver } \\
\text { problemas }\end{array}$} \\
\hline & TESLA & Consultores & TESLA & Consultores & TESLA & Consultores \\
\hline $\begin{array}{l}\text { Meio Ambiente: } \\
\text { Gestor e } \\
\text { funcionários }\end{array}$ & $\begin{array}{l}\text { O gestor não participou } \\
\text { das atividades, } \\
\text { tampouco esteve } \\
\text { presente nas demais } \\
\text { reuniões. Os usuários- } \\
\text { chave deste } \\
\text { departamento } \\
\text { assumiram toda a parte } \\
\text { de estruturação para si, } \\
\text { embora com pouco } \\
\text { envolvimento, } \\
\text { alinhando as suas } \\
\text { necessidades com as } \\
\text { funcionalidades do } \\
\text { portal. }\end{array}$ & $\begin{array}{l}\text { Para satisfazer os } \\
\text { usuários-chave, todas } \\
\text { as solicitações } \\
\text { operacionais eram } \\
\text { atendidas no desenho } \\
\text { do portal neste } \\
\text { departamento. Esse } \\
\text { posicionamento foi } \\
\text { ocasionado pela } \\
\text { ausência do gestor, } \\
\text { pois, dentre os três } \\
\text { departamentos iniciais } \\
\text { do projeto, este é o que } \\
\text { apresentava maior } \\
\text { resistência à } \\
\text { implantação. }\end{array}$ & $\begin{array}{l}\text { O gestor participou } \\
\text { somente da primeira } \\
\text { reunião e não esteve } \\
\text { mais presente para } \\
\text { trazer o direcionamento } \\
\text { estratégico. Os } \\
\text { usuários-chave não } \\
\text { possuíam visão } \\
\text { estratégica e a } \\
\text { ferramenta ficou } \\
\text { implementada somente } \\
\text { com opções } \\
\text { operacionais. }\end{array}$ & $\begin{array}{l}\text { O papel dos } \\
\text { consultores líderes } \\
\text { neste departamento foi } \\
\text { somente de } \\
\text { apresentação do portal } \\
\text { e de tentativa de } \\
\text { sensibilização da } \\
\text { equipe sobre a } \\
\text { importância do mesmo. } \\
\text { Não houve } \\
\text { aconselhamento } \\
\text { estratégico. }\end{array}$ & $\begin{array}{l}\text { O gestor não participou } \\
\text { do controle do projeto. } \\
\text { Essa atividade } \\
\text { repousou nos usuários- } \\
\text { chave, em consonância } \\
\text { com o gestor do projeto } \\
\text { de TI. O que lhes foi } \\
\text { ofertado inicialmente } \\
\text { em relação ao banco de } \\
\text { horas foi aceito e sem } \\
\text { solicitação de } \\
\text { acréscimo. }\end{array}$ & $\begin{array}{l}\text { O contato geralmente } \\
\text { era de um consultor } \\
\text { técnico no dia a dia que } \\
\text { repassava os problemas } \\
\text { a um consultor líder. } \\
\text { Apresentavam somente } \\
\text { relatórios básicos de } \\
\text { acompanhamento. }\end{array}$ \\
\hline
\end{tabular}

Nota. Fonte: Dados primários 
A participação e o envolvimento dos atores da empresa foram diferentes em cada um dos departamentos. Em dois deles não houve nenhum envolvimento do gestor. O usuário-chave da TI comentou: "Os gestores não têm prioridade sobre o projeto do portal, é muito difícil conseguir marcar reuniões com eles e, quando marcamos, muitas vezes eles não aparecem alegando compromissos mais importantes, aí fica difícil!" (Inf-02).

Essa situação também pôde ser constatada em duas reuniões do departamento de meio ambiente, cujo propósito era fazer o acompanhamento do projeto e realizar outra entrega. Embora o gestor da área estivesse convidado e confirmado, ele sequer passou pela reunião, que ficou a cargo dos usuários-chave.

Em outro departamento, porém, a participação foi ativa e sistemática. O gestor do departamento colocou: "busquei conhecer o que tinha de portal de segurança no mercado, fiz assinaturas e comecei a entender o que era um portal" (Inf-09). Esse benchmark forneceu ideias e seu papel foi ativo durante todo o processo. Tal situação facilitou a atuação do consultor em importantes decisões. Estes diferentes graus de envolvimento dos gestores, usuários-chave e demais funcionários ensejaram resultados diferentes em cada departamento.

Ninguém dos departamentos de RH e meio ambiente tinha experiência anterior com portais. É preciso dizer que os usuários-chave e as respectivas equipes se mostraram pouco proativas. Por exemplo, no departamento do meio ambiente, algumas reuniões agendadas não ocorreram sob a justificativa de compromissos mais importantes e, como o projeto precisava avançar, os consultores deixaram de discutir as soluções em reuniões e passaram a conversar individualmente com os usuários-chave, propondo soluções que pudessem satisfazê-los. Esses usuários, por sua vez, consideraram satisfatórias as soluções propostas pelo consultor.

Além disso, várias funcionalidades operacionais foram implementadas a partir do entendimento compartilhado de necessidades entre o usuário-chave e o consultor, sem suporte ou participação do nível tático dos departamentos, conforme já mencionado. O distanciamento dos diretores desses dois departamentos e do presidente favoreceu a livre negociação entre os envolvidos que, por serem técnicos, implantaram funcionalidades operacionais sem se preocuparem com o suporte estratégico almejado originalmente pela diretoria.

No departamento de segurança, as presenças ativas do gestor e do usuário-chave, bem como seu conhecimento prévio de portais corporativos, geraram melhores encaminhamentos para o consultor. Em todas as reuniões, o gestor trazia dúvidas, discutia funcionalidades e informações adicionais sobre possíveis integrações (por exemplo, da área de segurança com os programas de qualidade de vida no trabalho), e a implantação de novas funcionalidades (por exemplo, espaço de colaboração sobre temas específicos) era solicitada. Esse direcionamento garantiu uma solução de portal que ofereceu suporte à gestão do departamento e da empresa, obtendo, assim, um AE. O portal deste departamento serviu de caso de sucesso aos outros departamentos, mas não foi seguido em sua íntegra.

Ao analisar o papel do consultor responsável pelo processo de desenvolvimento do portal percebeu-se que nos momentos de negociação, o consultor (em especial os analistas presentes na empresa) foi responsável, em grande parte, pelas funcionalidades implementadas. Em algumas reuniões, apesar dos usuários solicitarem soluções individuais (abrangendo seu trabalho apenas), os analistas desenharam estruturas que, no futuro, poderiam integrar e suportar funcionalidades mais avançadas (por exemplo, padronização na forma de compartilhar versões de documentos no portal). Mesmo com essa intervenção do consultor, as funcionalidades entregues foram essencialmente operacionais.

Apesar do conhecimento e da experiência previamente acumulada pelo consultor na implementação de portais em outras grandes empresas, o processo de AE se perdeu em dois departamentos. O consultor (em especial o analista de negócios) conhecia os objetivos iniciais esperados com a implantação do portal, pois haviam sido especificados na contratação. Isso pode ser verificado na apresentação preparada pelo departamento de TI sobre os principais objetivos com a implantação do portal e também nos objetivos apresentados pelos consultores no início de cada reunião. 
Porém, durante a implantação, o processo de acomodação dos objetivos individuais que surgiram nos departamentos e a interação entre os atores envolvidos alteraram estes objetivos iniciais. Isso pode ser ilustrado no departamento de meio ambiente, no qual os objetivos individuais expressos pelos usuários-chave foram traduzidos diretamente em funcionalidades do site departamental.

Outro ponto a ser destacado é que o consultor desconhecia os detalhes do planejamento estratégico da TESLA e também os detalhes do seu negócio, pois seu contrato foi baseado em um banco de horas que contemplou a implementação do portal e não contemplou reuniões de exploração dos aspectos estratégicos. Soma-se a isso a ausência de planejamento estratégico formalizado em algumas áreas (RH e meio ambiente), bem como a falta de uma visão estratégica presente no dia a dia dos funcionários de nível operacional.

Verificou-se que, quando os objetivos estratégicos departamentais foram institucionalizados e disseminados durante o processo de implementação do portal e quando existiu a presença do gestor como guia, a obtenção do $\mathrm{AE}$ foi facilitada. A falta dessa visão estratégica em muitas situações oportunizou o surgimento de objetivos individuais, gerando soluções não alinhadas com o negócio da empresa. Essa situação havia sido destacada por Chatterjee, Grewal e Sambamurthy (2002), ao afirmarem que os gestores, através das suas crenças, valores e conhecimentos, proveem visão e diretrizes para sua equipe explorar os aspectos estratégicos da TI. Para esses autores, os gestores são os principais responsáveis por modificar a estrutura, introduzindo novas tecnologias, integrando-as e facilitando sua adoção.

A falta deste conteúdo estratégico no portal também foi ocasionada por uma falta de controle das atividades e de cobrança (resultados oriundos dos objetivos estratégicos), normalmente previstas na governança corporativa e não verificadas na empresa. Essa falta de conteúdo, assim como a não disseminação de elementos da estratégia, mencionada anteriormente, contribuiu para o surgimento de soluções individuais e para a perda dos objetivos estratégicos iniciais.

Apesar de o processo de implementação estar a cargo de um consultor que utilizou a mesma metodologia nos três departamentos, foram identificados resultados bem distintos. Isso evidencia que, de acordo com os atores envolvidos, adaptações na metodologia precisam ser realizadas para que os resultados esperados sejam efetivamente atingidos.

Visando complementar a análise apresentada, optou-se pelo referencial conceitual extraído de Benbya, Passiante e Belbaly (2004), detalhado na Figura 2. Ele foi adotado por destacar os principais fatores que afetam o uso dos portais corporativos e as inter-relações entre eles.

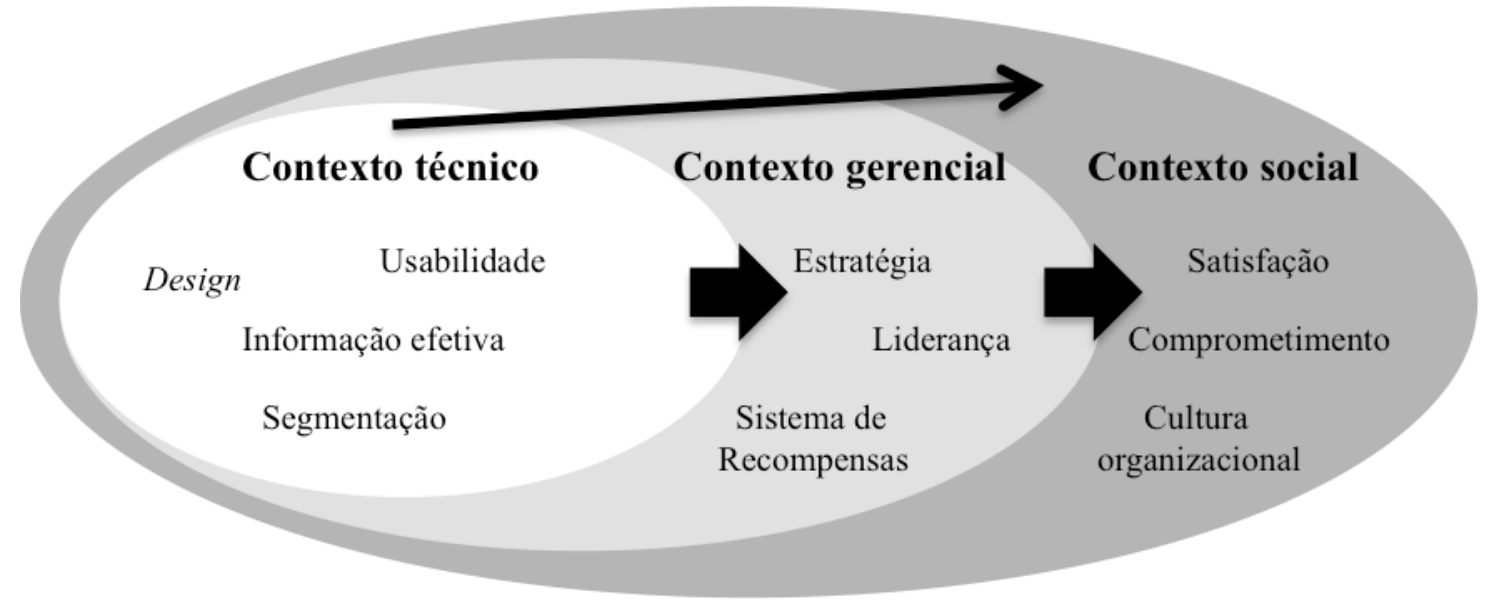

Figura 2. Fatores que Afetam o Uso dos Portais Corporativos

Fonte: Adaptada de Benbya, H., Passiante, G., \& Belbaly, N. A. (2004). Corporate portal: a tool for knowledge management synchronization (p. 215). International Journal of Information Management, 24(3), 201-220. doi: 10.1016/j.ijinfomgt.2003.12.012 
Com base nesse referencial, verificou-se que a preocupação de grande parte dos atores envolvidos no projeto recaiu essencialmente sobre o contexto técnico, relacionado ao design e à usabilidade. Esses elementos técnicos eram mais conhecidos pelo consultor, fazendo parte da sua competência essencial. Eles são mais controláveis e seu gerenciamento é facilitado pelo uso da ferramenta adotada na implementação do portal (Sharepoint).

Dentre os três contextos envolvidos na implementação de um portal, o técnico se configura como o mais restrito de todos. Como já mencionado, o contexto gerencial e o social têm um impacto maior na implantação, no uso e na disseminação do portal dentro da empresa, mesmo sendo condicionados pelo contexto técnico. É preciso apreender esses contextos.

Essa aprendizagem demanda tempo, porque envolve comunicação mais formal sobre aspectos essenciais do negócio, plano estratégico e indicadores de desempenho, e mais informal sobre relações de poder e mudanças organizacionais (Fisher, 1993). A organização matricial da TESLA também dificultou este aprendizado.

A análise realizada permitiu evidenciar uma preocupação do consultor e do usuário-chave da TI essencialmente voltada para o contexto técnico. Em várias reuniões sobre a estrutura do portal, realizadas sem a participação dos departamentos envolvidos, essa preocupação ficou muito evidente. A citação da fala de um dos consultores, "temos que pensar em como vai ficar o layout da tela e também nos aspectos de usabilidade ... como o usuário vai encontrar a informação", ilustra muito bem este aspecto (InfE01).

O papel do consultor no processo deveria figurar como um elo entre os três contextos, representados pelas duas setas centrais da figura. Baseado no conhecimento técnico que ele possui da ferramenta, ele poderia ser o articulador, juntamente com o nível tático, o dos objetivos estratégicos e o dos objetivos buscados com a implantação do novo portal. Mas isto requer conhecimento do contexto técnico da ferramenta de TI e das demandas do contexto social, sempre em consonância com o contexto gerencial. Apesar de toda a relação entre a empresa e os consultores estar lastreada em um contrato, que requeria entregas periódicas, ambos deveriam avançar em um entendimento prévio entre o negócio e a TI, objetivando o alinhamento entre as expectativas de ambos os lados. Essa etapa serviria para romper a barreira do contexto técnico e aproximar o contexto gerencial.

Como já assinalado, essa situação ocorreu somente no departamento de segurança. Já nos outros dois departamentos estudados, os consultores alternaram suas ações entre os contextos técnico e social, não atuando no contexto gerencial. Essa falta de orientação estratégica, influenciada pelo pouco envolvimento dos gestores, oportunizou o surgimento de soluções pontuais que satisfaziam os usuários operacionais sem qualquer visão estratégica. Esse movimento está representado pela seta mais estreita na Figura 2.

Em relação ao contexto gerencial, a mudança de foco dos gestores dos departamentos e a falta de um suporte mais efetivo durante o processo por parte da direção da empresa resultaram em uma liberdade muito grande de negociação entre os funcionários dos departamentos (os atores de nível operacional) e os consultores, fazendo com que o objetivo estratégico se perdesse ao longo do processo. Chatterjee et al. (2002) já haviam ressaltado que as crenças e os valores estratégicos inicialmente manifestados pela alta direção se perdem no processo caso não sejam seguidos por uma participação efetiva no processo de implementação. Devido a essa não participação dos gestores, o uso mais amplo do portal bem como seu impacto inter e intradepartamental ficaram limitados no processo de AE. Como já relatado, uma gestão englobando aspectos mais estratégicos só ocorreu no departamento de segurança, permitindo a obtenção de resultados mais abrangentes e próximos dos objetivos iniciais previstos para o portal.

Quando se analisam os três níveis hierárquicos da organização e seu relacionamento com os consultores no início do projeto, identifica-se um relacionamento intenso do nível tático interno com os consultores. Discutiram-se os três contextos (técnico, gerencial e social), com foco especial no contexto gerencial. Durante a execução do projeto, o nível tático muitas vezes delegou o trabalho para os usuários- 
chave que pertenciam ao nível operacional dos três departamentos e da TI, e assumiram o papel de operacionalizar e acompanhar a implantação do portal, trabalhando juntamente com os consultores.

Neste momento, as ações se concentraram nos contextos técnico e social operacional (necessidades individuais ou quase individuais), carecendo de ações para contemplar o nível gerencial. Essa falta de engajamento do nível tático foi potencializada pela pouca presença da direção no processo, pelas fragilidades do processo de comunicação durante a implementação e pela ausência de instrumentos de cobrança (governança).

Para que ocorra a comunicação entre os que trabalham no negócio e os que trabalham com TI, há a necessidade de um efetivo compartilhamento dos conhecimentos. Segundo A. F. Brodbeck, Rigoni e Hoppen (2009), a comunicação no processo de AE foi considerada por gestores de negócio e de TI brasileiros como o mais importante elemento para obter alinhamento.

\section{Considerações Finais}

A estratégia enquanto prática fundamentou a análise do papel do consultor no processo de implantação de um portal com objetivos estratégicos, envolvendo três níveis hierárquicos (estratégico, tático e operacional). Esta análise foi enriquecida com a observação de múltiplos atores, grupos e suas diferentes práxis (Jarzabkowski \& Spee, 2009). A abordagem adotada na pesquisa contribuiu para o estudo do relacionamento dos atores (e grupos) com os consultores (praticantes externos à organização), facilitando a compreensão nos vários níveis de práxis. Tal escolha permitiu compreender fenômenos como o surgimento de objetivos individuais, e como estes ocupam o lugar dos objetivos estratégicos num processo de $\mathrm{AE}$.

O consultor, pela falta de uma orientação estratégica clara por parte da empresa e por não ter superado essa fragilidade durante o processo de implementação, conduziu o processo de forma predominantemente técnica. Para cumprir o contrato, fez a entrega de soluções operacionais nos prazos acordados. Essas soluções atenderam os usuários do nível operacional no curto prazo, mas não contemplaram funções estratégicas originalmente almejadas. Para o atendimento deste último requisito, o consultor deve enfocar explicitamente os aspectos sociopolíticos e ter habilidades para tanto, conforme destaca por Bloomfield e Danieli (1995).

Percebe-se que o AE, na prática, não pode ser baseado apenas em um enfoque técnico (design) e econômico (horas previstas para o projeto, cronograma). Esse processo requer a consideração de elementos sociais não somente internos, mas também externos quando há consultores envolvidos. Esses elementos devem ser considerados na elaboração do contrato através da previsão de horas para este tipo de reuniões, da previsão de governança e de indicadores de eficácia. A preocupação insuficiente com os elementos sociais foi revelada durante a implantação do portal, no qual se evidenciaram os objetivos (compartilhados ou não), as visões dos atores e seus interesses pessoais. Estes elementos, muitas vezes, revelaram-se distanciados dos objetivos inicialmente estabelecidos e se voltaram para resultados mais tangíveis, de prazo mais curto e de menor risco.

Apesar de todo um movimento acadêmico chamar atenção para os aspectos sociais, como o estudo da dualidade da estrutura (Jones \& Karsten, 2008) e a análise das relações entre atores nas redes sociais (Ciborra, 2002), a pesquisa evidenciou que no dia a dia, ainda há uma dedicação insuficiente dos gestores e dos consultores na busca do entendimento desses elementos. Também foi mostrado que, muitas vezes, os gestores da empresa delegaram a responsabilidade aos consultores e usuários-chave de nível operacional, sendo que estes nem sempre tinham se apropriado da visão estratégica da empresa e do papel do projeto. Por outro lado, a acomodação dos consultores na sua competência técnica também ficou evidente durante o processo de implantação do portal, reduzindo a efetividade na obtenção do AE almejado. 
Como os consultores desempenham um papel fundamental na implantação de ferramentas de TI nas empresas, a principal contribuição deste estudo para o campo profissional é reiterar que a atuação desses atores externos à organização deve ser baseada na compreensão dos contextos técnicos, gerencial e social. Extrapolar o contexto técnico pode ser um diferencial para a efetividade da ação do consultor e, principalmente, para os ganhos das empresas-cliente no que tange à efetividade do processo de alinhamento.

Para concluir, cabe destacar que a contribuição teórica deste trabalho repousa em uma análise mais detalhada do papel do consultor externo no processo de AE baseada nos conceitos da estratégia enquanto prática. Esse processo foi fundamentado por muito tempo em modelos conceituais que, por sua estrutura, não capturavam detalhes dos processos. Importante ressaltar que as pesquisas qualitativas sobre o tema enfatizaram aspectos técnicos ou adotaram a priori visões de níveis hierárquicos definidos (geralmente o nível tático ou estratégico).

Nessa linha, a presente pesquisa, ao utilizar como bases teórica e metodológica as análises do dia a dia dos atores de diferentes níveis hierárquicos e também dos consultores, permitiu estudar o processo do $\mathrm{AE}$ de maneira mais sistemática, detalhada e completa. $\mathrm{O}$ entendimento do papel dos atores sociais internos e externos, em cada nível hierárquico, também foi determinante para a compreensão do processo de alinhamento e das suas fragilidades. A dependência do AE e da efetiva participação da alta direção no processo, por exemplo, já haviam sido destacadas por Campbell, Key e Avison (2005), quando analisaram as conexões entre os envolvidos com o negócio e a TI.

Os resultados foram obtidos a partir da análise do AE relacionado à implementação de um só portal, de caráter estratégico. Apesar de um só caso ter sido analisado, vários dos aspectos encontrados no processo de implementação foram confirmados pela literatura consultada, o que contribui para a sua validade. Dentre eles, cabe salientar a credibilidade organizacional do consultor (em todos os níveis hierárquicos envolvidos) destacada por Markus e Benjamin (1996), as habilidades sociopolíticas do consultor mencionadas por Bloomfield e Danieli (1995), a efetividade da comunicação entre os atores dos processos negociais e da TI, abordada por A. F. Brodbeck et al. (2009), e a necessidade da análise de macro e micro quando do estudo de elementos relativos à estratégia de uma organização, estudada por Jarzabkowski e Spee (2009) e Whittington (2006).

Considerando que a problemática da implementação de ferramentas de TI e da efetividade do AE ainda persiste, julga-se adequada a realização de novos estudos sobre o papel do consultor na implementação de sistemas de vocação estratégica. Por ser um importante ator que está bastante presente na implementação de ferramentas de TI, a sua efetiva integração ainda precisa ser mais estudada na prática.

Para tanto, o recente estudo de Gerow, Thatcher e Grover (2014), que distingue alinhamento intelectual dos atores envolvidos e alinhamento operacional dos processos, pode ser de valia. Estudos dessa natureza poderão reforçar os resultados sobre a importância dos aspectos sociais no processo de $\mathrm{AE}$ aqui apresentados e, quem sabe, influenciar a adequada formação e aquisição de competências dos que trabalham em consultoria.

Dentre essas competências, destacam-se as visões do negócio e do planejamento estratégico, e a comunicação (interpessoal na e com a organização). A abordagem utilizada, a discussão e a análise dos resultados sugerem encaminhamentos para uma possível melhoria no entendimento do alinhamento, trazendo à reflexão a atuação do consultor de TI, suas práticas e sua compreensão do locus do alinhamento. 


\section{Referências}

Abib, G., Hoppen, N., \& Hayashi, P. (2013). Observação participante em estudos de administração da informação no Brasil. Revista de Administração de Empresas, 53(6), 606-616. doi: 10.1590/S0034-759020130608

Angrosino, M. (2009). Etnografia e observação participante. Porto Alegre: Artmed.

Avgerou, C., Ciborra, C., \& Land, F. (2004). The social study of information and communication technology: innovation, actors and contexts. Oxford, USA: Oxford University Press.

Balogun, J., Jarzabkowski, P., \& Seidl, D. (2007). Strategizing: the challenges of practice perspective. Human Relations, 60(1), 5-27. doi: 10.1177/0018726707075703

Benbya, H., Passiante, G., \& Belbaly, N. A. (2004). Corporate portal: a tool for knowledge management synchronization. International Journal of Information Management, 24(3), 201-220. doi: 10.1016/j.ijinfomgt.2003.12.012

Bloomfield, B. P., \& Danieli, A. (1995). The role of management consultants in the development of information technology: the indissoluble nature of socio-political and technical skills. Journal of Management Studies, 32(1), 23-46. doi: 10.1111/j.1467-6486.1995.tb00644.x

Brodbeck, A. F., \& Hoppen, N. (2003). Alinhamento estratégico entre os planos de negócio e de tecnologia de informação: um modelo operacional para implantação. Revista de Administração Contemporânea, 7(3), 9-33. doi: 10.1590/S1415-65552003000300002

Brodbeck, A. F., Rigoni, E. H., \& Hoppen, N. (2009). Strategic alignment maturity between business and information technology in Southern Brazil. Journal of Global Information Technology Management, 12(2), 5-32. doi: 10.1080/1097198X.2009.10856489

Brodbeck, H. J., Brodbeck, A. F., Canépa, P. V., \& Bobsin, D. (2010). Configuração de um processo de seleção, aquisição e implementação de ERP considerando os grupos sociais envolvidos. Revista Eletrônica de Sistemas de Informação, 9(1), art. 2. Recuperado de http://revistas.facecla.com.br/index.php/reinfo/article/download/579/476. doi: 10.5329/RESI.2010.0901002

Campbell, B., Key, R., \& Avison, D. (2005). Strategic alignment: a practitioner's perspective. Journal of Enterprise Information Management, 18(6), 653-664.

Campbell, B., \& Peppard, J. (2007). The co-evolution of business information systems' strategic alignment: an exploratory study. Retrieved from http://www.som.cranfield.ac.uk/som/dinamiccontent/media/isrc/coevolution\%20of\%20strategic\%20alignment.pdf

Carter, C., Clegg, S. R., \& Kornberger, M. (2008). Strategy as practice? Strategic Organization, 6(1), 83-99. doi: 10.1177/1476127007087154

Chan, Y. (2002). Why haven't we mastered alignment? The importance of the informal organizational structure. MIS Quarterly Executive, 1(2), 97-112.

Chan, Y., \& Reich, B. H. (2007). IT alignment: what have we learned? Journal of Information Technology, 22(4), 297-315. doi: 10.1057/palgrave.jit.2000109

Chan, Y., Sabherwal, R., \& Thatcher, J. B. (2006). Antecedents and outcomes of strategic IS alignment: an empirical investigation. IEEE Transactions on Engineering Management, 53(1), 27-47. doi: 10.1109/TEM.2005.861804 
Chatterjee, D., Grewal, R., \& Sambamurthy, V. (2002). Shaping up for e-commerce: institutional enablers of the organizational assimilation of web technologies. MIS Quarterly, 26(2), 65-89. doi: $10.2307 / 4132321$

Ciborra, C. (1997). De profundis? Deconstructing the concept of strategic alignment. Scandinavian Journal of Information Systems, 9(1), 67-82.

Ciborra, C. (2001). From control to drift: the dynamics of corporate information infrastructures. Oxford: Oxford University Press.

Ciborra, C. (2002). The labyrinths of information: challenging the wisdom of systems. New York: Oxford Press.

Correia, F. B. C., Feitosa, M. G. G., \& Vieira, N. S. (2010). A consultoria como oportunidade de aprendizagem para as organizações não governamentais: um estudo de caso na cidade de Recife/PE. Revista de Administração da UFSM, 3(2), 245-259.

Donadone, J. C. (1995). A difusão de conceitos gerenciais, imprensa de negócios e o mercado de consultoria nos anos 90. Gestão.Org, 3(1), 26-38. Recuperado de http://www.revista.ufpe.br/gestaoorg/index.php/gestao/article/viewFile/131/113

Dubé, L., \& Paré, G. (2003). Rigor in information systems positivist case research: current practices, trends, and recommendations. MIS Quarterly, 27(4), 597-635. doi: 10.2307/30036550

Fisher, D. (1993). Communication in organizations (2nd ed.). St. Paul, MIN: West Publishing Company.

Gerow, J. E., Thatcher, J. B., \& Grove, V. (2014). (Forthcoming). Six types of IT-business strategic alignment: an investigation of the constructs and their measurement. European Journal of Information Systems, 23, 1-27. doi: 10.1057/ejis.2014.6

Grant, G. (2010). Reconceptualizing the concept of business and IT alignment: from engineering to agriculture [Editorial]. European Journal of Information Systems, 19(6), 619-624. doi: $10.1057 /$ ejis. 2010.50

Henderson, J. C., \& Venkatraman, N. (1993). Strategic alignment: leveraging information technology for transforming organizations. IBM Systems Journal, 32(1), 4-16.

Jarzabkowski, P., \& Seidl, D. (2008). The role of strategy meetings in the social practice strategy. Organization Studies, 29(11), 1391-1426. doi: 10.1177/0170840608096388

Jarzabkowski, P., \& Spee, A. P. (2009). Strategy-as-practice: a review and future directions for the field. International Journal of Management Reviews, 11(1), 69-95. doi: 10.1111/j.14682370.2008.00250.x

Johnson, G., Melin, L., \& Whittington, R. (2003). Micro-strategy and strategising. Journal of Management Studies, 40(1), 3-22. doi: 10.1111/1467-6486.t01-2-00002

Joia, L. A., \& Souza, J. G. A. de (2009). Articulando modelos de alinhamento estratégico de tecnologia da informação. Cadernos EBAPE. BR, 7(2), 252-269. Recuperado de http://www.scielo.br/pdf/cebape/v7n2/a06v7n2.pdf. doi: 10.1590/S1679-39512009000200006

Jones, M. R., \& Karsten, H. (2008). Giddens's structuration theory and information system research. MIS Quarterly, 32(1), 127-157.

Kirk, J., \& Miller, M. L. (1986). Reliability and validity in qualitative research. Newbury Park, CA: Sage Publications. 
Krippendorff, K. (1980). Content analysis: an introduction to its methodology. Thousand Oaks, CA: Sage Publications.

Lee, S. M., Kim, K., Paulson, P., \& Park, H. (2008). Developing a socio-technical framework for business IT alignment. Industrial Management \& Data Systems, 108(9), 1167-1181. doi: $10.1108 / 02635570810914874$

Lobo, P. L. (2013). Terceirização de TI: inovação desbanca redução de custos. Recuperado de http://convergenciadigital.uol.com.br/cgi/cgilua.exe/sys/start.htm?infoid=35383\&sid=5\#.VBRb zfldX19

Luftman, J. (2000). Assessing business-IT alignment maturity. Communications of the Association of Information Systems, 4(14), 1-51.

Luftman, J., Zadeh, H. S., Dersken, B., Santana, M., Rigoni, E. H., \& Huang, Z. D. (2012). Key information technology and management issues 2011-12: an international study. Journal of Information Technology, 27(3), 198-212. doi: 10.1057/jit.2012.14

Lunardi, G. L., Becker, J. L., \& Maçada, C. G. (2010). Impacto da adoção de mecanismos de governança de TI no desempenho da gestão de TI: uma análise baseada na percepção dos executivos. Revista de Ciências da Administração, 12(28), 11-39. doi: 10.5007/2175-8077.2010v12n28p11

Maciel, C. O., \& Augusto, P. O. M. (2013). A practice turn e o movimento social da estratégia como prática. Revista de Administração Mackenzie, 14(2), 155-178.

Markus, M. L., \& Benjamin, R. I. (1996). Change agentry: the next IS frontier. MIS Quarterly, 20(4), 385-407. doi: 10.2307/249561

Meirelles, F. (2008). Prefácio. In A. L. Albertin \& O. P. Sanchez, Outsourcing de TI: impactos, dilemas, discussões e casos reais (pp.7-9). São Paulo: Atlas.

Preston, D. S., \& Karahanna, E. (2009). Antecedents of IS strategic alignment: a nomological network. Information Systems Research, 20(2), 159-179. doi: 10.1287/isre.1070.0159

Prospects. (2012). Consultant: job description. Retrieved from http://www.prospects.ac.uk/it_consultant_job_description.htm

Reich, B. H., \& Benbasat, I. (1996). Measuring the linkage between business and information technology objectives. MIS Quarterly, 20(1), 55-81. doi: 10.2307/249542

Reich, B. H., \& Benbasat, I. (2000). Factors that influence the social dimension of alignment between business and information technology objectives. MIS Quarterly, 24(1), 81-113. doi: $10.2307 / 3250980$

Rigoni, E. H., Dwivedi, R., \& Hoppen, N. (2010). IT governance and business-it strategic alignment commitment: a study of Brazilian firms. International Journal of Global Management Studies Professional, 2(1), 1-20.

Ruhl, J. (1997). The computer consultant's guide (2nd ed.). New York: John Wiley \& Sons.

Serva, M., \& Jaime, P., Jr. (1995). Observação participante pesquisa em administração: uma postura antropológica. Revista de Administração de Empresas, 35(3), 64-79. doi: 10.1590/S003475901995000300008

Simonsen, J. (1999). How do we take care of strategic alignment? Constructing a design approach. Scandinavian Journal of Information Systems, 11(2), 1-22. 
Strauss, A., \& Corbin, J. (2008). Pesquisa qualitativa: técnicas e procedimentos para o desenvolvimento de teoria fundamentada (2a ed.). Porto Alegre: Artmed.

Tan, F. B., \& Gallup, R. B. (2006). Aligning business and information systems thinking: a cognitive approach. IEEE Transactions of Engineering Management, 53(2), 223-237. doi: 10.1109/TEM.2006.872243

Trauth, E. M., \& O'Connor, B. (1991). A study of the interaction between information technology and society: an illustration of combined qualitative research methods. In H. E. Nissen, H. K. Klein, \& R. Hirschheim (Eds.), Information systems research: contemporary approaches and emergent traditions (pp. 131-144). Elsevier North-Holland, Inc.

Whittington, R. (2004). Estratégia após o modernismo: recuperando a prática. Revista de Administração de Empresas, 44(4), 44-53.

Whittington, R. (2006). Completing the practice turn in strategy research. Organization Studies, 27(5), 613-634. doi: 10.1177/0170840606064101

Wilson, D., \& Jarzabkowski, P. (2004). Pensando e agindo estrategicamente: novos desafios para a análise estratégica. Revista de Administração de Empresas, 44(4), 11-20.

Yin, R. K. (2005). Estudo de caso: planejamento e métodos (3a ed.). Porto Alegre: Bookman.

\section{Dados dos Autores}

Gustavo Abib

Av. Pref. Lothario Meissner, 632, Jardim Botânico, 80210-170, Curitiba, PR, Brasil. E-mail: gustavo.abib@gmail.com

Norberto Hoppen

Av. Unisinos, 950, 93022-000, São Leopoldo, RS, Brasil. E-mail: norbertohoppen@ gmail.com 